\title{
A previous hamstring injury affects kicking mechanics in soccer players
}

\author{
Archit NAVANDAR *, Santiago VEIGA, Gonzalo TORRES, David CHORRO, Enrique NAVARRO
}

Faculty of Sports Sciences, Universidad Politécnica de Madrid, Madrid, Spain

*Corresponding author: Archit Navandar, Faculty of Sports Sciences, Universidad Politécnica de Madrid, C/ Martín Fierro 7, 28040 Madrid, Spain. E-mail: archit.navandar@upm.es

\section{A B S T R A C T}

BACKGROUND: Although the kicking skill is influenced by limb dominance and sex, how a previous hamstring injury affects kicking has not been studied in detail. Thus, the objective of this study was to evaluate the effect of sex and limb dominance on kicking in limbs with and without a previous hamstring injury.

METHODS: Forty-five professional players (males: N. $=19$, previously injured players $=4$, age $=21.16 \pm 2.00$ years; females: N. $=19$, previously injured players $=10$, age $=22.15 \pm 4.50$ years) performed 5 kicks each with their preferred and non-preferred limb at a target $7 \mathrm{~m}$ away, which were recorded with a three-dimensional motion capture system. Kinematic and kinetic variables were extracted for the backswing, leg cocking, leg acceleration and follow through phases.

RESULTS: A shorter backswing (20.20 $\pm 3.49 \%$ vs. $25.64 \pm 4.57 \%)$, and differences in knee flexion angle $\left(58 \pm 10^{\circ} v s .72 \pm 14^{\circ}\right)$ and hip flexion velocity $(8 \pm 0 \mathrm{rad} / \mathrm{s}$ vs. $10 \pm 2 \mathrm{rad} / \mathrm{s})$ were observed in previously injured, non-preferred limb kicks for females. A lower peak hip linear velocity $(3.50 \pm 0.84 \mathrm{~m} / \mathrm{s} v s .4 .10 \pm 0.45 \mathrm{~m} / \mathrm{s})$ was observed in previously injured, preferred limb kicks of females. These differences occurred in the backswing and leg-cocking phases where the hamstring muscles were the most active. A variation in the functioning of the hamstring muscles and that of the gluteus maximus and iliopsoas in the case of a previous injury could account for the differences observed in the kicking pattern. CONCLUSIONS: Therefore, the effects of a previous hamstring injury must be considered while designing rehabilitation programs to re-educate kicking movement.

(Cite this article as: Navandar A, Veiga S, Torres G, Chorro D, Navarro E. A previous hamstring injury affects kicking mechanics in soccer players. J Sports Med Phys Fitness 2018;58:1815-22. DOI: 10.23736/S0022-4707.18.07852-0)

KEY WORDS: Biomechanical phenomena - Kinetics - Sex characteristics.

$\mathrm{T}$ he hamstring muscle strain is one of the most common muscle injuries in soccer. ${ }^{1}$ Hamstring strain injuries account for $10-16 \%$ of all injuries in professional soccer, 2,3 and $22 \%$ of players sustained at least one hamstring injury during a season of European football. ${ }^{1}$ On an average, 18 days and 3-3.5 matches are missed per hamstring strain injury. 3,4 Studies with athletes using motion capture and ground reaction forces ${ }^{5-7}$ indicate that hamstring muscle strain injuries most commonly occur during maximal or sub-maximal sprinting. ${ }^{8}$ They specifically occur during the latter part of the swing phase when the hamstrings work to decelerate knee extension in preparation for heel strike.4, 6, 9 Apart from maximal and sub-maximal sprinting, hamstring strain injuries can also be caused during kicking, ${ }^{10}$ and it has been shown that the injuries caused by kicking are more severe than those caused while sprinting. ${ }^{11}$

Kicking technique has been explained with an open kinetic chain model, ${ }^{12}$ following proximal to distal sequence of segmental motions, ${ }^{13}$ where a good inter-limb coordination, ${ }^{14}$ and an inter-segmental transfer of energy are critical. ${ }^{15}$ The kicking motion can be divided into four phases based on the joint movements in the sagittal plane (Figure 1): 16 backswing, leg cocking, leg acceleration, and follow through. It is in the follow through phase, when the hip is flexed and the knee begins to flex form a fully extended position, that the hamstring muscle complex is most susceptible to sustaining an injury. ${ }^{17,18}$ 
TABLE I.-Characteristics of professional soccer players in the study.

\begin{tabular}{|c|c|c|c|c|c|c|c|}
\hline & $\mathrm{N}$. & Age (years) & Weight (kg) & $\begin{array}{l}\text { Uninjured dominant } \\
\text { limbs (N.) }\end{array}$ & $\begin{array}{l}\text { Uninjured non- } \\
\text { dominant limbs (N.) }\end{array}$ & $\begin{array}{l}\text { Injured dominant } \\
\text { limbs (N.) }\end{array}$ & $\begin{array}{l}\text { Injured non-dominant } \\
\text { limbs (N.) }\end{array}$ \\
\hline Male & 19 & $21.16 \pm 2.00$ & $71.46 \pm 6.22$ & 16 & 18 & 3 & 1 \\
\hline Female & 26 & $22.15 \pm 4.50$ & $60.71 \pm 9.48$ & 20 & 22 & 6 & 4 \\
\hline Total & 45 & $21.73 \pm 3.63$ & $65.25 \pm 9.72$ & 36 & 40 & 9 & 5 \\
\hline
\end{tabular}

players who were uninjured and declared match-fit by the medical and coaching staff at the time of data capture were included in the study. Players having a history of ACL or MCL injury in the previous two seasons were also excluded from the study. All players $(\mathrm{N} .=45$, Table I) provided written informed consent in accordance with the departmental and university ethical procedures and following the principles outlined in the Declaration of Helsinki. Participants were asked to fill up a questionnaire which asked about their preferred limb, preferred playing position and their injury history in the hamstring muscle group. Only players having suffered a grade 1, 2 or 3 hamstring injury which caused them to miss the subsequent match in the previous two years $(\mathrm{N} .=14)$ were considered as having an "injured limb". All players who were injured had suffered a unilateral injury (Table I).

\section{Data capture}

A six-camera VICON ${ }^{\circledR}$ motion capture system (Oxford Metrics Ltd, Oxford, UK) at $250 \mathrm{~Hz}$ was used to capture the kicking motion. The data capture was carried out on a $15 \mathrm{~m} \mathrm{x} 3 \mathrm{~m}$ strip of FIFA ${ }^{\mathrm{TM}}$ approved artificial turf with participants wearing soccer shoes specific for artificial turf. A lower body model was used to capture and analyze the data. The data capture session was divided into static and dynamic capture sessions. For the static capture, which was used to determine joint centers, twenty-four retro-reflective markers with a diameter of $14 \mathrm{~mm}$ were attached to the anatomical landmarks symmetrically on the left and right side on the of each participant's body. The markers were attached to the anterior and posterior superior iliac spines, the heads of the greater trochanter of the femur, the lateral thigh, the medial and lateral epicondyles of the femur, the lateral shank, the lateral and medial malleoli, the calcaneus, and the heads of the second and fifth metatarsals. To identify the marker positions on the metatarsal heads, the participants were asked to lift and lower their hallux repeatedly, and the point about which the movement of the toes were hinged along the second and fifth metatarsals was where the markers were placed. Four hemispherical retro-reflective markers (diameter 14 $\mathrm{mm}$ ) were placed on a FIFA ${ }^{\mathrm{TM}}$ approved Adidas $^{\circledR}$ soccer ball (diameter $=225 \mathrm{~cm}$, pressure $=12 \mathrm{psi}$ ) to determine the timing of impact and the resultant ball velocity after the impact from the motion capture data. For the warm-up and dynamic capture, the markers attached to the greater trochanter, medial epicondyles, the medial malleoli and the second metatarsal heads were removed. In the dynamic capture, each participant had to kick the ball at a $1 \mathrm{~m} \mathrm{x} 1$ $\mathrm{m}$ target $7 \mathrm{~m}$ away (the distance being selected because of space restrictions). They were instructed to kick as hard possible with a four-step run-up such that the support leg was placed on the platform. Kicks were repeated until five instep kicks with the preferred and non-preferred limb each entered the target for each player.

\section{Data analysis}

To facilitate analysis, each trial was divided into different intervals using characteristic time instances similar to phases previously defined in literature (Figure 1). ${ }^{16}$ The characteristic time instances were: toe-off of kicking leg (TO), maximum extension of the hip (MHE), maximum flexion of the knee (MKF), ball impact (BI); and the end of the follow through (EFT), when the $5^{\text {th }}$ metatarsal marker reached the highest position. To determine the frame of ball impact, first, a virtual marker, "BallCentre" which was the mid-point between the diametrically opposite ball markers, B1 and B2, was calculated. The frame in which this marker was displaced by a value greater than $3 \mathrm{~mm}$ from its initial position was determined, and the first frame before this instance was defined as that of ball impact. The impact of the foot with the ball is known to cause a serious distortion of data near impact when the data is filtered. ${ }^{14}$ One frame before and five after ball impact were deleted and interpolated using Vicon ${ }^{\circledR}$ 's cubic spline "fill gaps" algorithm. ${ }^{39}$ The raw data was then filtered using Woltring's method ${ }^{40}$ with a mean square error of $4 \mathrm{~mm}^{2}$. The velocity of "BallCentre" was computed, and the trial with the median value of velocity among the five kicks with each limb was selected for further analysis. The lower body was modelled as a link-segment model composed of the foot, the shank, the thigh and the pelvis. Each segment was connected to the other through joint centers at the ankle, knee and hip. Local coordinate systems were defined such that 
the origin was at the distal marker attached to the segment, the longitudinal axis was the $\mathrm{Z}$ (the positive direction being from the distal to proximal segment), the medio-lateral axis being $\mathrm{Y}$ (the positive direction being from lateral to medial), and $\mathrm{X}$ being mutually perpendicular to both. A standard inverse dynamics procedure ${ }^{41}$ was used to determine the reaction moments of the kicking limb and the reaction forces of the support limb. The adduction, flexion and internal rotation moments were determined as positive moments, while abduction, extension and external moments were represented as negative moments. To determine the kinetic parameters, segmental inertial parameters were taken from de Leva's modification to the Zatsiorsky model. 42 The force and moment data was normalized in function with the body mass of the participant. All the calculations were carried out using the Vicon ${ }^{\circledR}$ BodyBuilder software (VICON; Oxford Metrics Ltd.).

\section{Statistical analysis}

A 3-way ANOVA was used to compare dependent variables with previous injury, sex and limb dominance being the independent factors. Peak linear velocities, normalized time intervals, and sagittal plane kinematic variables of the kicking leg affected by the hamstring muscle ${ }^{6}$ at MHE, MKF, BI and EFT were compared. Peak flexion and extension moments were also contrasted. The statistical analysis was carried out using SPSS ${ }^{\circledR} 20.0$ (SPSS Inc., Chicago, IL, USA) and the level of statistical significance was set at 0.05 . When a significant effect was observed between the ANOVA levels, multiple comparisons were performed with the Bonferroni correction to avoid type I error, and the results were interpreted with $95 \%$ confidence intervals (CIs) and effect sizes (as partial $\eta^{2}$ values). The threshold values for small, medium and large effect sizes were set as $0.01,0.06$ and 0.08 respectively. 43,44 Since there was only one male player who had sustained an injury in the non-preferred limb, the comparison between the injured and uninjured limb for kicks with the non-preferred limb in males would only be reported and not discussed.

\section{Results}

Differences in the kicking parameters in the previously injured and uninjured limbs were found in the backswing $\left(F_{5,76}=3.61, \mathrm{P}=0.012\right.$, partial $\left.\eta^{2}=0.061\right)$ and leg cocking $\left(F_{5,77}=4.94, \mathrm{P}=0.029\right.$, partial $\left.\eta^{2}=0.057\right)$ phases. In the nonpreferred limb kicks, the backswing phase was shorter for the previously injured group $(20.20 \pm 3.49 \%)$ when

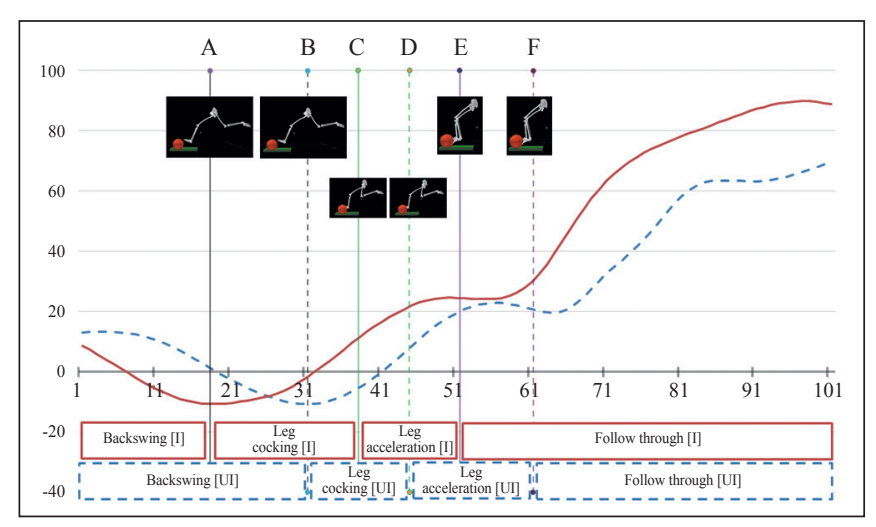

Figure 2.-Hip flexion and extension angle $\left(^{\circ}\right)$ in the non-preferred, female kick for the previously injured and uninjured limbs. The different phases for each kick are also represented in the figure.

Curve: injured (I); dotted curve: uninjured (UI); A: max hip ext I; B: max hip ext UI; C: $\max$ knee flex I; D: $\max$ knee flex UI; E: ball impact I; F: ball impact UI.

compared to previously uninjured group $(25.64 \pm 4.57 \%$, $\mathrm{P}=0.012$, partial $\eta^{2}=0.075$, Figure 2), independent of sex. Specifically, in the case of female soccer players, a lower knee flexion for injured group was observed at the end of this phase $\left(\mathrm{P}=0.048\right.$, partial $\eta^{2}=0.047$, Table II). Also in the backswing phase, the injured females reached a smaller maximal hip linear velocity $\left(\mathrm{P}=0.037\right.$, partial $\left.\eta^{2}=0.052\right)$ while kicking with the preferred limb (Table II, Figure 3). Subsequently in the leg cocking phase, female soccer players attained a lower hip flexion velocity at the end

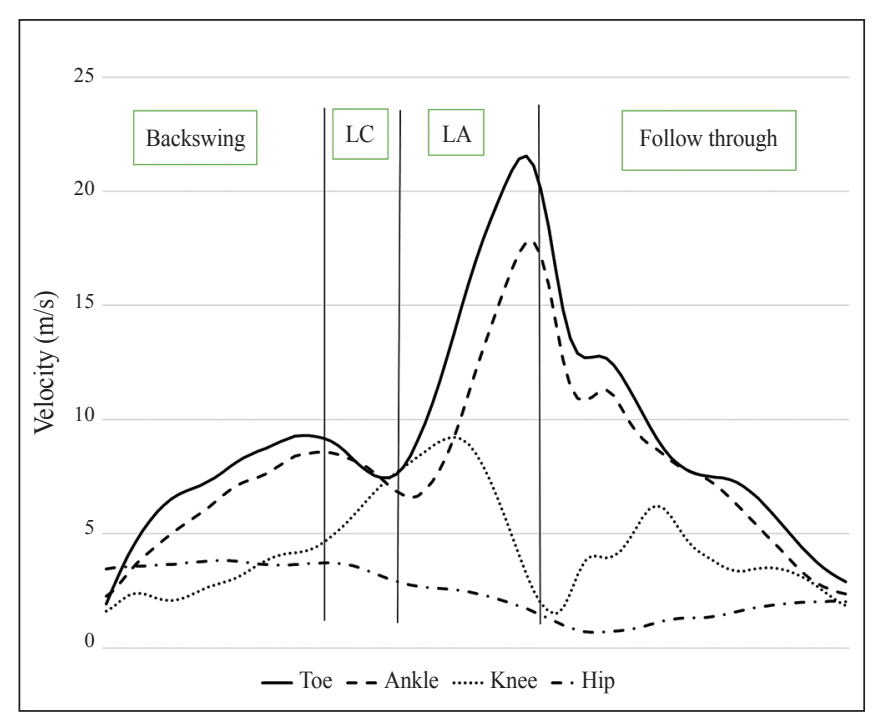

Figure 3.-Sequence of linear velocities for articulations in the kicking limb. 
TABLE II.-Angles and angular velocities at the end of each of the phases (mean \pm standard deviation) of male and females professional soccer players when kicking with their dominant and non-dominant limb.

\begin{tabular}{|c|c|c|c|c|c|c|c|c|c|c|}
\hline & & & Backswing $\left({ }^{\circ}\right)$ & Leg cocking $\left({ }^{\circ}\right)$ & $\begin{array}{c}\text { Leg acceleration } \\
\left({ }^{\circ}\right)\end{array}$ & $\begin{array}{c}\text { Follow } \\
\text { through }\left({ }^{\circ}\right)\end{array}$ & $\begin{array}{c}\text { Backswing } \\
(\mathrm{rad} / \mathrm{s})\end{array}$ & $\begin{array}{c}\text { Leg cocking } \\
(\mathrm{rad} / \mathrm{s})\end{array}$ & $\begin{array}{c}\text { Leg acceleration } \\
(\mathrm{rad} / \mathrm{s})\end{array}$ & $\begin{array}{l}\text { Follow through } \\
(\mathrm{rad} / \mathrm{s})\end{array}$ \\
\hline \multirow[t]{4}{*}{ ND hip } & $\mathrm{F}$ & UI & $-13 \pm 10$ & $14 \pm 9$ & $30 \pm 9$ & $83 \pm 18$ & $0 \pm 0$ & $10 \pm 2 *$ & $-2 \pm 2$ & $2 \pm 3$ \\
\hline & & I & $-8 \pm 7$ & $13 \pm 5$ & $30 \pm 10$ & $83 \pm 15$ & $0 \pm 0$ & $8 \pm 0 *$ & $-1 \pm 1$ & $1 \pm 3$ \\
\hline & M & UI & $-10 \pm 9$ & $16 \pm 9$ & $30 \pm 10$ & $93 \pm 15$ & $0 \pm 0$ & $10 \pm 2$ & $0 \pm 3$ & $2 \pm 3$ \\
\hline & & I & $-1 \pm$ & $21 \pm$ & $37 \pm$ & $110 \pm$ & $0 \pm$ & $10 \pm$ & $0 \pm$ & $-1 \pm$ \\
\hline \multirow[t]{4}{*}{ D hip } & $\mathrm{F}$ & UI & $-15 \pm 9$ & $12 \pm 10$ & $27 \pm 11$ & $86 \pm 17$ & $0 \pm 0$ & $12 \pm 2$ & $-3 \pm 3$ & $1 \pm 2$ \\
\hline & & I & $-14 \pm 11$ & $14 \pm 10$ & $30 \pm 8$ & $89 \pm 12$ & $0 \pm 0$ & $11 \pm 2$ & $-1 \pm 2$ & $-1 \pm 2$ \\
\hline & M & UI & $-13 \pm 8$ & $15 \pm 6$ & $28 \pm 9$ & $97 \pm 16$ & $0 \pm 0$ & $11 \pm 1$ & $-1 \pm 3$ & $3 \pm 2$ \\
\hline & & I & $-12 \pm 4$ & $11 \pm 4$ & $23 \pm 4$ & $90 \pm 13$ & $0 \pm 0$ & $11 \pm 1$ & $-1 \pm 2$ & $4 \pm 1$ \\
\hline \multirow[t]{4}{*}{ ND knee } & $\mathrm{F}$ & UI & $72 \pm 14^{*}$ & $114 \pm 12$ & $58 \pm 12$ & $26 \pm 14$ & $14 \pm 3$ & $0 \pm 1$ & $-26 \pm 4$ & $4 \pm 4$ \\
\hline & & I & $58 \pm 10 *$ & $110 \pm 8$ & $51 \pm 15$ & $27 \pm 14$ & $17 \pm 1$ & $0 \pm 1$ & $-25 \pm 3$ & $2 \pm 4$ \\
\hline & M & UI & $72 \pm 8$ & $116 \pm 9$ & $46 \pm 14$ & $28 \pm 16$ & $16 \pm 2$ & $0 \pm 1$ & $-28 \pm 5$ & $4 \pm 5$ \\
\hline & & I & $75 \pm$ & $122 \pm$ & $66 \pm$ & $29 \pm$ & $20 \pm$ & $0 \pm$ & $-31 \pm$ & $0 \pm$ \\
\hline \multirow[t]{4}{*}{ D knee } & $\mathrm{F}$ & UI & $67 \pm 19$ & $112 \pm 11$ & $45 \pm 9$ & $26 \pm 12$ & $15 \pm 3$ & $0 \pm 1$ & $-28 \pm 5$ & $4 \pm 5$ \\
\hline & & I & $73 \pm 6$ & $113 \pm 13$ & $45 \pm 9$ & $31 \pm 14$ & $14 \pm 3$ & $0 \pm 1$ & $-26 \pm 4$ & $1 \pm 4$ \\
\hline & M & UI & $74 \pm 10$ & $118 \pm 8$ & $43 \pm 11$ & $27 \pm 20$ & $17 \pm 5$ & $0 \pm 1$ & $-32 \pm 4$ & $5 \pm 3$ \\
\hline & & I & $79 \pm 10$ & $118 \pm 9$ & $44 \pm 5$ & $36 \pm 19$ & $16 \pm 2$ & $0 \pm 1$ & $-32 \pm 3$ & $9 \pm 1$ \\
\hline
\end{tabular}

A positive value indicates flexion and negative value extension.

UI: uninjured limb; I: injured limb; F: female; M: male; ND: non-dominant limb kick; D: dominant limb kick.

*Significantly different with $\mathrm{P}<0.05$.

TABLE III.-Peak linear velocities (mean \pm standard deviation) of male and female professional soccer players when kicking with their dominant and non-dominant limb.

\begin{tabular}{lccccc}
\hline & & & Ball $(\mathrm{m} / \mathrm{s})$ & Knee $(\mathrm{m} / \mathrm{s})$ & Hip $(\mathrm{m} / \mathrm{s})$ \\
\hline Non-dominant & Female & Uninjured & $22.19 \pm 2.86$ & $8.33 \pm 1.06$ & $3.81 \pm 0.60$ \\
& & Injured & $23.25 \pm 1.26$ & $8.50 \pm 0.58$ & $4.00 \pm 0.00$ \\
& Male & Uninjured & $26.06 \pm 2.78$ & $9.22 \pm 0.81$ & $4.22 \pm 0.65$ \\
Dominant & & Injured & 27.00 & 9.00 & 4.00 \\
& \multirow{2}{*}{ Female } & Uninjured & $25.25 \pm 2.47$ & $8.05 \pm 0.83$ & $3.10 \pm 0.45^{*}$ \\
& & Injured & $24.17 \pm 2.48$ & $10.13 \pm 0.82$ & $4.30 \pm 0.84^{*}$ \\
& Male & Uninjured & $28.63 \pm 1.75$ & $9.67 \pm 0.58$ & $4.33 \pm 0.62$ \\
\hline
\end{tabular}

*Significantly different from the uninjured group with $\mathrm{P}<0.05$.

of the leg-cocking phase if they belonged to the injured group $\left(\mathrm{P}=0.019\right.$, partial $\eta^{2}=0.067$, Table II), this being more prominent in the non-preferred limb kicks $(\mathrm{P}=0.030$, partial $\eta^{2}=0.058$, Table II). No other statistically significant differences were found between the injured and uninjured group in the angles and angular velocities (Table II) in either of these phases. The peak hip flexion moment and peak knee extension moment, which also occurred in these phases were similar between the injured and uninjured kicking limbs.

In the leg acceleration phase, when the hip flexed and the knee extended, similar angles and angular velocities were found between the injured and uninjured kicking limbs (Table II), independent of sex. No differences were found in the peak knee linear velocity, which occurred in this phase, and the peak ball velocities, just after ball impact, were also similar between the different groups (Table III).
Finally, in the follow through phase, the kinematic (Table II) and kinetic (Table IV) variables were similar between the injured and the uninjured limbs across all groups.

\section{Discussion}

The injured and uninjured limb kicking technique of professional soccer players was compared and differences in the backswing and leg-cocking phases were observed. In these kicking phases, theoretically, the hamstring muscles were the most active (extending the hip and flexing the knee) along with other hip extensors (gluteus maximus) and flexors (iliopsoas). A previous hamstring injury appeared to alter the coordination between these muscles, which affected the kicking technique differently in injured preferred or non-preferred leg.

A previous injury to the non-preferred limbs resulted in 
TABLE IV._-Peak kicking leg moments (mean \pm standard deviation) of male and female professional soccer players when kicking with their dominant and non-dominant limb.

\begin{tabular}{|c|c|c|c|c|c|c|}
\hline & & & $\begin{array}{l}\text { Peak hip flexion } \\
\text { moment }(\mathrm{Nm} / \mathrm{kg})\end{array}$ & $\begin{array}{l}\text { Peak hip extension } \\
\text { moment }(\mathrm{Nm} / \mathrm{kg})\end{array}$ & $\begin{array}{l}\text { Peak knee flexion } \\
\text { moment }(\mathrm{Nm} / \mathrm{kg})\end{array}$ & $\begin{array}{l}\text { Peak knee extension } \\
\text { moment }(\mathrm{Nm} / \mathrm{kg})\end{array}$ \\
\hline \multirow[t]{4}{*}{ Non-dominant } & \multirow[t]{2}{*}{ Female } & Uninjured & $3.76 \pm 1.14$ & $-2.67 \pm 1.24$ & $1.57 \pm 0.6$ & $-1 \pm 0.32$ \\
\hline & & Injured & $3.75 \pm 0.5$ & $-2.5 \pm 0.58$ & $1.25 \pm 0.5$ & $-1 \pm 0$ \\
\hline & \multirow[t]{2}{*}{ Male } & Uninjured & $3.44 \pm 0.86$ & $-3.28 \pm 0.89$ & $1.67 \pm 0.49$ & $-1.17 \pm 0.38$ \\
\hline & & Injured & 4 & -4 & 2 & -1 \\
\hline \multirow[t]{4}{*}{ Dominant } & \multirow[t]{2}{*}{ Female } & Uninjured & $3.95 \pm 0.76$ & $-3.55 \pm 1.05$ & $1.7 \pm 0.57$ & $-1.1 \pm 0.31$ \\
\hline & & Injured & $4.67 \pm 1.37$ & $-4 \pm 1.41$ & $1.83 \pm 0.75$ & $-1.33 \pm 0.52$ \\
\hline & \multirow[t]{2}{*}{ Male } & Uninjured & $4.13 \pm 0.72$ & $-3.88 \pm 0.72$ & $1.94 \pm 0.25$ & $-1.19 \pm 0.4$ \\
\hline & & Injured & $4 \pm 0$ & $-3.33 \pm 0.58$ & $2 \pm 0$ & $-1.33 \pm 0.58$ \\
\hline
\end{tabular}

A positive value indicates flexion and negative value extension.

a shorter time to peak hip extension compared to the uninjured limb (Figure 1) in both male and female players and a lower knee flexion angle was noted in the case of previously injured female soccer players (Table II). In the backswing phase, the hamstring muscle fibers worked to extend the hip and flex the knee. ${ }^{45}$ The hamstrings work in conjunction with the gluteus maximus to extend the hip, the latter being the principal extensor of the femur. A lower activity of the gluteus maximus and hamstrings in this phase for previously injured athletes could possibly account for the smaller backswing phase. Recent research has shown that higher amounts of gluteal and trunk muscle activity during the airborne phases of sprinting were associated with a lower risk of hamstring injuries. ${ }^{46}$ Hence, there is a need for better neuromuscular control in the proximal joints, ${ }^{46}$ and this has been incorporated in returnto-play programs 47,48 as well. Probably a better neuromuscular control of the gluteus maximus in the previously injured limb, especially if it is a non-preferred limb, could help overcome the technique deficit, allowing the players to sustain the hip extension for a longer time.

Both the biceps femoris and the semitendinosus are flexors of the knee, and in the case of female soccer players, a lower activity of the previously injured hamstring muscles could contribute to the smaller knee flexion angle at the end of the backswing phase in the non-preferred limb (Table II). A recent study in recreational, healthy, male Australian-rules football players showed that the semitendinosus is more likely than the other two-joint hamstrings to exhibit kicking-induced fatigue. ${ }^{17}$ Although the participants were not apparently fatigued in this study (they performed five kicks with either limb), performing repeated kicking actions with a previously injured non-preferred limb could possibly affect the hamstrings in a similar manner to fatigued, healthy hamstrings. Repeated sprint abilities have been used as functional tests post soccer injuries, ${ }^{49}$ and form an essential part of rehabilitation programs posthamstring muscle complex injury. ${ }^{50}$ Perhaps, including repeated kicking as a part of the rehabilitation and injury prevention programs would help soccer players.

In the leg cocking phase, the female soccer players kicking with a previously injured, non-preferred limb showed a lower hip flexion velocity at the end of the leg cocking phase (Table III). However, both the previously injured and uninjured limbs reached similar knee flexion angles at a similar time interval, and the knee flexion velocities (at the end of the backswing phase) were similar as well (Table III). Thus, from these findings, a previous injury's effect on the non-preferred limb is more pronounced at the hip, rather than at the knee and appears to affect other surrounding muscle groups which are responsible for hip flexion while the knee flexes. In this case, the authors believe that the iliopsoas muscles are affected, which are the primary flexors of the hip. Previous research has shown that exercises of the lumbo-pelvic muscles produced indirect activation of the hamstrings, improving its mechanical response. ${ }^{25,47,51}$ As previously stated, a better neuromuscular control of the muscles of the hip joint should form an important part of return-to-play and injury prevention programs.

In the preferred limb, differences were seen only in the case of a previous injury in female soccer players who were inhibited them from reaching a maximal linear velocity in the hip similar to that in the uninjured preferred limbs (Table II). Kicking is a proximal-to-distal movement, 52,53 with peak velocities also being reached in the same sequential order, ${ }^{52}$ with the peak hip velocity being reached in the backswing phase, the peak knee, ankle and toe velocities in the leg acceleration phase (Figure 3). The lower peak hip linear velocities thus could be accounted for by either an altered neuromuscular activity of the hip extensors, the gluteus maximus, ${ }^{46}$ or the previously injured hamstring muscles; 54 or possibly, a lower strength of the hip exten- 
sors after toe-off of the kicking leg. However, no other statistically significant differences are seen in other biomechanical parameters of the preferred limb kick. The optimal sequencing of movements in the preferred limb kicks ${ }^{55}$ is probably responsible in overcoming the deficits that were seen in the non-preferred limb kicking mechanics.

No differences were observed in the leg acceleration phase where the hamstring muscles did not play a predominant role. In this phase the knee extends as the hip continues to flex, and stronger quadriceps of the professionals favor this movement. ${ }^{56}$ No differences were found in the follow through phase, contrary to the hypothesis presented in this study and to previous research in soccer. ${ }^{18}$ The differences with the previous research ${ }^{17}$ could be due to the surface on which the kicks were performed (artificial turf $v s$. laboratory surface), type of kick selected (in-step with both limbs $v s$. in-step and side-foot with preferred limb alone) and the different statistical analyses performed in the two studies (3-way ANOVA vs. non-parametric MannWhitney U Test). No differences were also observed in the kinetics of the kicking limb (Table IV).

The findings from this study suggest that coaches and practitioners have to treat an injury sustained in the nonpreferred limb differently from that in the preferred limb. Improving neuromuscular control in the non-preferred limb, especially with movements similar to those in the backswing and leg cocking phases, incorporating repeated kicking in training and rehabilitation programs, and working on bilateral symmetry could perhaps help players with previously injured non-preferred limbs.

\section{Limitations of the study}

One of the limitations of this study was the limited number of previously injured players. Although fourteen players were injured compared with thirty-one uninjured players (Table I), each limb was considered independent to the other and all players had suffered a unilateral hamstring injury. Studies on professional soccer have found that $22 \%$ of the players of a team sustained a hamstring injury per season, ${ }^{1}$ and 17-22-year-old age groups sustained fewer hamstring strain injuries than the older soccer players, ${ }^{3}$ and the male soccer players in this study fell in that group (Table I). One must also be careful about the generalization of these results. Given the relatively small sample size, especially in the case of male soccer players performing 2 and 3-way ANOVA analyses have slightly underpowered the results. More studies analyzing the effect of a previous hamstring strain injury on the kicking skill are needed to confirm findings of the present research.

\section{Conclusions}

This study gives evidence that a previous injury to the hamstrings can affect the kicking technique especially in the backswing and leg cocking phases. These differences were mainly seen in the kinematics of female soccer players. No differences were seen in the leg acceleration or follow through phases, nor in the kinetics of the soccer players. The soccer kicking technique is known to be different across sex and limb dominance, and the presence of a previous injury was somewhat affected. This should be taken into account on the return to play programs in order to re-educate the kicking technique.

\section{References}

1. Ekstrand J, Waldén M, Hägglund M. Hamstring injuries have increased by 4\% annually in men's professional football, since 2001: a 13-year longitudinal analysis of the UEFA Elite Club injury study. Br J Sports Med 2016;50:731-7.

2. Noya J. Análisis de la incidencia lesional en el fútbol profesional español en la temporada 2008-2009. Universidad Politecnica de Madrid; 2015.

3. Woods C, Hawkins RD, Maltby S, Hulse M, Thomas A, Hodson A; Football Association Medical Research Programme. The Football Association Medical Research Programme: an audit of injuries in professional football — analysis of hamstring injuries. Br J Sports Med 2004;38:36-41.

4. Petersen J, Hölmich P. Evidence based prevention of hamstring injuries in sport. Br J Sports Med 2005;39:319-23.

5. Chumanov ES, Heiderscheit BC, Thelen DG. Hamstring musculotendon dynamics during stance and swing phases of high-speed running. Med Sci Sports Exerc 2011;43:525-32.

6. Lee MJ, Reid SL, Elliott BC, Lloyd DG. Running biomechanics and lower limb strength associated with prior hamstring injury. Med Sci Sports Exerc 2009;41:1942-51.

7. Schache AG, Blanch PD, Dorn TW, Brown NA, Rosemond D, Pandy MG. Effect of running speed on lower limb joint kinetics. Med Sci Sports Exerc 2011;43:1260-71.

8. Schache AG, Dorn TW, Blanch PD, Brown NA, Pandy MG. Mechanics of the human hamstring muscles during sprinting. Med Sci Sports Exerc 2012;44:647-58.

9. Guex K, Millet GP. Conceptual framework for strengthening exercises to prevent hamstring strains. Sports Med 2013;43:1207-15.

10. Liu H, Garrett WE, Moorman CT, Yu B. Injury rate, mechanism, and risk factors of hamstring strain injuries in sports: A review of the literature. J Sport Health Sci 2012;1:92-101.

11. Brooks JH, Fuller CW, Kemp SP, Reddin DB. Incidence, risk, and prevention of hamstring muscle injuries in professional rugby union. Am J Sports Med 2006;34:1297-306.

12. Lees A, Asai T, Andersen TB, Nunome H, Sterzing T. The biomechanics of kicking in soccer: a review. J Sports Sci 2010;28:805-17.

13. Kellis E, Katis A. Biomechanical characteristics and determinants of instep soccer kick. J Sports Sci Med 2007;6:154-65.

14. Nunome H, Ikegami Y, Kozakai R, Apriantono T, Sano S. Segmental dynamics of soccer instep kicking with the preferred and non-preferred leg. J Sports Sci 2006;24:529-41.

15. Dörge HC, Anderson TB, Sørensen H, Simonsen EB. Biomechanical differences in soccer kicking with the preferred and the non-preferred leg. J Sports Sci 2002;20:293-9. 
16. Lees A. Biomechanics applied to soccer skills. In: Williams AM, ed. Science and Soccer. 3 ed. London: Routledge; 2013:218-23.

17. Duhig SJ, Williams MD, Minett GM, Opar D, Shield AJ. Drop punt kicking induces eccentric knee flexor weakness associated with reductions in hamstring electromyographic activity. J Sci Med Sport 2017;20:595-9.

18. Navandar A, Gulino M, Antonio R, Navarro E. Effect of hamstring injuries on kicking in soccer using inverse dynamics. Biomecánica 2013;21:7-19.

19. Opar DA, Williams MD, Timmins RG, Hickey J, Duhig SJ, Shield AJ. Eccentric hamstring strength and hamstring injury risk in Australian footballers. Med Sci Sports Exerc 2015;47:857-65.

20. Croisier JL, Ganteaume S, Binet J, Genty M, Ferret JM. Strength imbalances and prevention of hamstring injury in professional soccer players: a prospective study. Am J Sports Med 2008;36:1469-75.

21. Greig M, Siegler JC. Soccer-specific fatigue and eccentric hamstrings muscle strength. J Athl Train 2009;44:180-4.

22. Askling CM, Tengvar M, Thorstensson A. Acute hamstring injuries in Swedish elite football: a prospective randomised controlled clinical trial comparing two rehabilitation protocols. Br J Sports Med 2013;47:953-9.

23. Sole G, Milosavljevic S, Nicholson HD, Sullivan SJ. Selective strength loss and decreased muscle activity in hamstring injury. J Orthop Sports Phys Ther 2011;41:354-63.

24. Freckleton G, Pizzari T. Risk factors for hamstring muscle strain injury in sport: a systematic review and meta-analysis. Br J Sports Med 2013;47:351-8.

25. Navarro E, Chorro D, Torres G, García C, Navandar A, Veiga S. A review of risk factors for hamstring injury in soccer: a biomechanical approach. Eur J Hum Mov 2015;34:52-74.

26. Petersen J, Thorborg K, Nielsen MB, Hölmich P. Acute hamstring injuries in Danish elite football: a 12-month prospective registration study among 374 players. Scand J Med Sci Sports 2010;20:588-92.

27. Croisier JL. Factors associated with recurrent hamstring injuries. Sports Med 2004;34:681-95.

28. Cross KM, Gurka KK, Saliba S, Conaway M, Hertel J. Comparison of hamstring strain injury rates between male and female intercollegiate soccer athletes. Am J Sports Med 2013;41:742-8.

29. Silder A, Thelen DG, Heiderscheit BC. Effects of prior hamstring strain injury on strength, flexibility, and running mechanics. Clin Biomech (Bristol, Avon) 2010;25:681-6.

30. Hägglund $M$, Waldén $M$, Ekstrand J. Injuries among male and female elite football players. Scand J Med Sci Sports 2009;19:819-27.

31. Krustrup P, Mohr M, Ellingsgaard H, Bangsbo J. Physical demands during an elite female soccer game: importance of training status. Med Sci Sports Exerc 2005;37:1242-8.

32. Billaut F, Bishop D. Muscle fatigue in males and females during multiple-sprint exercise. Sports Med 2009;39:257-78.

33. Katis A, Kellis E, Lees A. Age and gender differences in kinematics of powerful instep kicks in soccer. Sports Biomech 2015;14:287-99.

34. Shan G. Influence of gender and experience on the maximal instep soccer kick. Eur J Sport Sci 2009;9:107-14.

35. Barfield WR, Kirkendall DT, Yu B. Kinematic instep kicking differences between elite female and male soccer players. J Sports Sci Med $2002 ; 1: 72-9$

36. Daneshjoo A, Rahnama N, Mokhtar AH, Yusof A. Bilateral and unilateral asymmetries of isokinetic strength and flexibility in male young professional soccer players. J Hum Kinet 2013;36:45-53.
37. Sinclair J, Fewtrell D, Taylor PJ, Atkins S, Bottoms L, Hobbs SJ Three-dimensional kinematic differences between the preferred and non-preferred limbs during maximal instep soccer kicking. J Sports Sci 2014;32:1914-23.

38. Fousekis K, Tsepis E, Vagenas G. Lower limb strength in professional soccer players: profile, asymmetry, and training age. J Sports Sci Med 2010;9:364-73

39. Reid M, Elliott B, Alderson J. Shoulder joint loading in the high performance flat and kick tennis serves. Br J Sports Med 2007;41:884-9.

40. Woltring $H$. On optimal smoothing and derivate estimation from noisy displacement data in biomechanics. Hum Mov Sci 1985;4:229-45.

41. Winter DA. Biomechanics and Motor Control of Human Movement. 4 ed. New York: John Wiley and Sons; 2009.

42. de Leva P. Adjustments to Zatsiorsky-Seluyanov's segment inertia parameters. J Biomech 1996;29:1223-30.

43. Richardson JT. Eta squared and partial eta squared as measures of effect size in educational research. Educ Res Rev 2011;6:135-47.

44. Cohen J. Eta-squared and partial eta-squared in fixed factor ANOVA designs. Educ Psychol Meas 1973;33:107-12.

45. Beltran L, Ghazikhanian V, Padron M, Beltran J. The proximal hamstring muscle-tendon-bone unit: a review of the normal anatomy, biomechanics, and pathophysiology. Eur J Radiol 2012;81:3772-9.

46. Schuermans J, Danneels L, Van Tiggelen D, Palmans T, Witvrouw E. Proximal Neuromuscular Control Protects Against Hamstring Injuries in Male Soccer Players: A Prospective Study With Electromyography Time-Series Analysis During Maximal Sprinting. Am J Sports Med 2017;45:1315-25.

47. Mendiguchia J, Martinez-Ruiz E, Edouard P, Morin JB, MartinezMartinez F, Idoate F, et al. A Multifactorial, Criteria-based Progressive Algorithm for Hamstring Injury Treatment. Med Sci Sports Exerc 2017;49:1482-92

48. Myer GD, Chu DA, Brent JL, Hewett TE. Trunk and hip control neuromuscular training for the prevention of knee joint injury. Clin Sports Med 2008;27:425-48. [ix.]

49. Padulo J, Attene G, Ardigò LP, Bragazzi NL, Maffulli N, Zagatto AM, et al. Can a Repeated Sprint Ability Test Help Clear a Previously Injured Soccer Player for Fully Functional Return to Activity? A Pilot Study. Clin J Sport Med 2017;27:361-8.

50. van der Horst N, Backx F, Goedhart EA, Huisstede BM; HIPS-Delphi Group. Return to play after hamstring injuries in football (soccer): a worldwide Delphi procedure regarding definition, medical criteria and decision-making. Br J Sports Med 2017;51:1583-91.

51. Heiderscheit BC, Sherry MA, Silder A, Chumanov ES, Thelen DG. Hamstring strain injuries: recommendations for diagnosis, rehabilitation, and injury prevention. J Orthop Sports Phys Ther 2010;40:67-81.

52. Lees A, Nolan L. The biomechanics of soccer: a review. J Sports Sci 1998; 16:211-34.

53. Juarez D, López De Subijana C, Mallo J, Navarro E. Acute effects of endurance exercise on jumping and kicking performance in top-class young soccer players. Eur J Sport Sci 2011;11:191-6.

54. Sole G, Milosavljevic S, Nicholson H, Sullivan SJ. Altered muscle activation following hamstring injuries. Br J Sports Med 2012;46:118-23.

55. Ball KA. Kinematic comparison of the preferred and non-preferred foot punt kick. J Sports Sci 2011;29:1545-52.

56. Gil S, Gil J, Ruiz F, Irazusta A, Irazusta J. Anthropometrical characteristics and somatotype of young soccer players and their comparison with the general population. Biol Sport 2010;27:17-24.

Conflicts of interest.-The authors certify that there is no conflict of interest with any financial organization regarding the material discussed in the manuscript. Article first published online: January 10, 2018. - Manuscript accepted: January 4, 2018. - Manuscript revised: December 19, 2017. - Manuscript received: June 6, 2017. 